\title{
Stress and polyamine metabolism in fungi
}

\section{Laura Valdés-Santiago and José Ruiz-Herrera*}

Departamento de Ingeniería Genética, Unidad Irapuato, Centro de Investigación y de Estudios Avanzados del Instituto Politécnico Nacional, Irapuato, México

\section{Edited by:}

Antonio F. Tiburcio, Universitat de Barcelona, Spain

\section{Reviewed by:}

Antonio F. Tiburcio, Universitat de

Barcelona, Spain

Oscar A. Ruiz, Instituto de

Investigaciones

Biotecnológicas-Instituto

Tecnológico de Chascomús,

Argentina

\section{${ }^{*}$ Correspondence:}

José Ruiz-Herrera, Departamento de

Ingeniería Genética, Unidad

Irapuato, Centro de Investigación y

de Estudios Avanzados del Instituto

Politécnico Nacional, Km 9.6,

Libramiento Norte, Carretera

Irapuato-León, Apartado Postal

36821 Irapuato, México

e-mail: jruiz@ira.cinvestav.mx
Fungi, as well as the rest of living organisms must deal with environmental challenges such as stressful stimuli. Fungi are excellent models to study the general mechanisms of the response to stress, because of their simple, but conserved, signal-transduction and metabolic pathways that are often equivalent to those present in other eukaryotic systems. A factor that has been demonstrated to be involved in these responses is polyamine metabolism, essentially of the three most common polyamines: putrescine, spermidine and spermine. The gathered evidences on this subject suggest that polyamines are able to control cellular signal transduction, as well as to modulate protein-protein interactions. In the present review, we will address the recent advances on the study of fungal metabolism of polyamines, ranging from mutant characterization to potential mechanism of action during different kinds of stress in selected fungal models.

Keywords: polyamines, stress response, polyamine mutants, fungi, metabolism

\section{INTRODUCTION}

Sudden changes in the external conditions can directly impact the internal environment of all living organisms, and can disrupt their homeostasis and normal physiology. Therefore, cells have developed complex systems to identify the status of their environment, and rapidly generate defense systems against environmental stress (Gasch, 2007; Lushchak, 2011; Montibus et al., 2013). An effective procedure to obtain information on the mechanisms regulating the stress response is the identification of pathways or specific genes suffering changes in their expression under stress conditions. Accordingly, it has been shown that a large number of genes are affected in their expression when an organism responds to an environmental stress. Many of these genes are conserved among fungi, including those involved in carbohydrate metabolism, protein metabolism, defense against reactive oxygen species (ROS), intracellular signaling, etc. (Giaever et al., 2002; Gasch, 2007). Among the known elements related with stress response are polyamines, as it has been widely demonstrated in plants (Galston and Sawhney, 1990; Alcazar et al., 2010; Gill and Tuteja, 2010a; Gupta et al., 2013). However, in recent years, investigations into the molecular genetics of fungal polyamine metabolism have led to the isolation of mutants altered in this function that show alterations in their response to stress. The importance of polyamine participation in the response to stress has been highlighted by the increasing number of reports describing the changes occurring in polyamine concentrations induced in response to diverse forms of stress. Accordingly, in the present review we describe the recent genetic and molecular evidences illustrating the role of polyamine metabolism in the responses of fungi to stress.

\section{POLYAMINE METABOLISM IN FUNGI BIOSYNTHESIS OF POLYAMINES}

Putrescine, spermidine and spermine are low-molecular-mass aliphatic cations critical to cell survival (Tabor and Tabor, 1984), and the pathways for their biosynthesis have been analyzed in all the kingdoms of living organisms [e.g., see Valdes-Santiago et al., 2012a]. However, there are some basic differences in the distribution of polyamines among them. In general, it is accepted that in fungi, as well as in animals, there is only one mechanism to produce putrescine de novo: by decarboxylation of ornithine by the enzyme ornithine decarboxylase (Odc, E.C.4.1.1.17), which is the first and rate-limiting enzyme in the synthesis of polyamines. In most fungi decarboxylation of ornithine is the only route to putrescine synthesis, however, in plants there is an additional route to produce putrescine: the decarboxylation of L-arginine by arginine decarboxylase (for more details of the general pathway in plants refer Alcazar et al., 2010; Gupta et al., 2013). Nevertheless, some authors have reported arginine decarboxylase activity in fungi such as Ceratocystis minor, Verticillium dahliae, Colletotrichum gleosporoides, and Gigaspora rosea, suggesting that both, arginine and ornithine decarboxylase enzymes could be involved in putrescine biosynthesis (Khan and Minocha, 1989; Weerasooriya et al., 2003; Sannazzaro et al., 2004). Putrescine is converted to spermidine by the addition of an aminopropyl group. $S$-adenosylmethionine decarboxylase (Samdc; E.C.4.1.1.50) is responsible for the formation of the donor of the aminopropyl group, decarboxylated S-adenosylmethionine (dcSAM), and spermidine synthase (Spe, E.C.2.5.1.16) is the transferase of the aminopropyl group from dcSAM to putrescine. Finally, spermidine is converted to spermine by a similar reaction, resulting in the transfer of an 
aminopropyl group to spermidine by spermine synthase (Sps; E.C.2.5.1.22) (see Figure 1). It should be noticed that this last step does not occur in most fungi, which accordingly contain only putrescine and spermidine (Nickerson et al., 1977). An ortholog of the gene encoding Sps is found only in the subphylum Saccharomycotina of the Ascomycota phylum which include few human pathogens and at least 10 phytopathogenic species (Suh et al., 2006; Pegg and Michael, 2010). Also interesting is to mention that SPE gene is present in members of Basidiomycota subphyla as a bifunctional gene encoding spermidine synthase and saccharopine dehydrogenase, the last enzyme involved in lysine biosynthesis (Leon-Ramirez et al., 2010). Regarding polyamine distribution, in general, eukaryotes have low putrescine content and a high content of spermidine and spermine, while prokaryotes have a higher concentration of putrescine than spermidine (Manni et al., 1987). A difference between fungi and plants is the presence of thermospermine, an isomer of spermine that has not been found in fungi (Fuell et al., 2010; Takano et al., 2012)

\section{RETRO-CONVERSION OF POLYAMINES}

In fungi, polyamines are oxidized to putrescine by the pathway shown in Figure 1. The first step is the acetylation of the aminopropyl group of polyamines, a reaction catalyzed by spermine or spermidine $N^{1}$-acetyltrasferase (Ssat; E.C. 2.3.1.57), to give either $N^{1}$-acetyl-spermidine or $N^{1}$-acetyl-spermine. These are in turn degraded by a polyamine oxidase (Pao; E.C. 1.5.3.11), with the formation of either putrescine or spermidine. Polyamine acetyltransferases and polyamine oxidases have been reported to be present in yeast as well as in other fungi (Yamada et al., 1980; Chattopadhyay et al., 2003b; Landry and Sternglanz, 2003; Liu et al., 2005; Valdes-Santiago et al., 2010). The ability to direct back-conversion of spermine to spermidine by spermine oxidase such as occurs in animals has been reported in plants and it is other dissimilarity between plants and fungi (Tavladoraki et al., 1998; Alcazar et al., 2006). In plants, redundancy of genes such as diamino oxidases or polyamine oxidases genes has been documented (Alcazar et al., 2006; Ono et al., 2012).

\section{REGULATION OF POLYAMINE SYNTHESIS}

Modulation of polyamine biosynthesis is mostly achieved by the degradation of Odc protein, as it has been reported in different species including Schizosaccharomyces pombe, Neurospora crassa, and Saccharomyces cerevisiae [(Barnett et al., 1988; Toth and Coffino, 1999) for review see (Ivanov et al., 2006)]. The regulator of Odc is the protein ornithine decarboxylase antizyme (Az) (Hayashi et al., 1996). Az interacts with Odc to be degraded by the proteasome in an ubiquitin independent manner (Zhang et al., 2003). Among fungi, the regulatory mechanism of $\mathrm{Az}$ is conserved [for review, see (Sorais et al., 2003)]. As indicated above, it was demonstrated that in S. cerevisiae, the degradation of Odc occurs without ubiquitination, as also happens in mammalian cells (Gandre and Kahana, 2002; Ivanov et al., 2006), and the identification of genes encoding Az from other fungi, suggests that the mechanism may be widely distributed in these organisms (Ivanov et al., 2006; Ivanov and Atkins, 2007). A peculiarity of fungi is that they present a single antizyme ortholog, while mammalian cells posses several antizyme encoding genes (Coffino, 2001a,b; Kurian et al., 2011). As expected, it is known that Az is positively regulated by polyamine levels. The mechanism for this regulation involves a translational frameshift in the open reading frame (ORF) in the encoding gene, through which a second ORF that encodes the active protein is established. In S. cerevisiae an unusual mechanism for the control of Az synthesis was unveiled (Kurian et al., 2011). Accordingly, the authors made the surprising discovery that at low polyamine levels $\mathrm{Az}$ acquires a

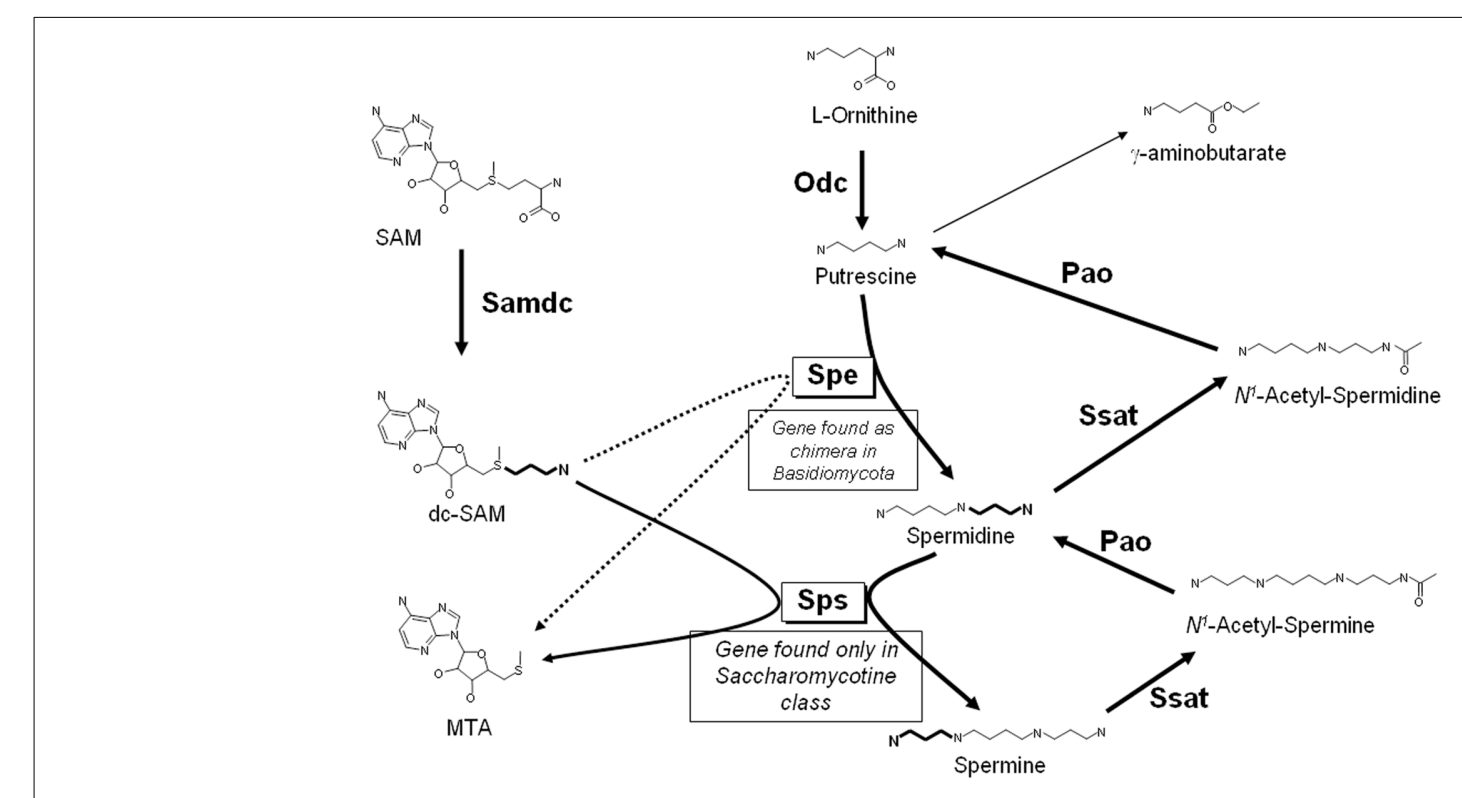

FIGURE 1 | General pathway for the biosynthesis and catabolism of polyamines in fungi. 
conformation that arrest its own synthesis, but high concentrations of polyamines bind, not to the regulatory region of the gene, but directly to the Az polypeptide, thus avoiding that it acquires such conformation, and promoting the completion of its synthesis Other regulatory mechanisms of the metabolism of polyamines occur at the levels of Odc, Ssat, and Pao, due to their early and rapid responses to external stimuli (Vujcic et al., 2003; Wallace et al., 2003). Additionally, the existence of regulatory sequence elements in the $5^{\prime}$ and $3^{\prime}$ of $O D C$ regions in $N$. crassa are related with changes in the rate of synthesis of Odc, and with changes in the abundance of ODC mRNA (Williams et al., 1992; Hoyt et al., 2000).

Contrary to fungi, plants posses several copies of the genes involved in polyamine metabolism which increase the complexity of polyamine regulation. As an example, in Arabidopsis thaliana there are two genes encoding $A d c 1$ and $A d c 2$, the first one is presented in all tissues and it is constitutively expressed, while the second one responds to some abiotic stresses (Soyka and Heyer, 1999; Perez-Amador et al., 2002). Likewise, Spd1 and Spd2 are the genes encoding spermidine synthase in A. thaliana (Imai et al., 2004; Ge et al., 2006).

Regard SAMDC, it is synthesized as a proenzyme, it has been demonstrated that putrescine induces the cleavage of the proenzyme in a specific amino acid to produce the active and mature enzyme (Pegg et al., 1998). In plants there is an additional regulation control at transcriptional level. Plant Samdc contain a tiny $5^{\prime}$-uORF and introns in $5^{\prime}$ leader sequence that regulate their expression (Hu et al., 2005). The absence of Az homolog in plant genomes corroborates the predominance of SAMDC as the regulator of polyamine homeostasis (Illingworth and Michael, 2012).

\section{INTERACTIONS WITH OTHER METABOLIC PATHWAYS}

The pleiotropic effects observed in polyamine mutants may be due to the relationships existing between polyamines and other metabolic pathways. As an example, ornithine, the precursor of putrescine not only is considered a key regulator of polyamine biosynthesis, but it may also regulate the pathways for glutamate transformation to arginine and to proline. Indirectly, it can also regulate putrescine catabolism, contributing to the aminobutiric acid content of the cells, since putrescine can be converted into $\Delta^{1}$-pyrroline by an amino oxidase, and this compound is metabolized to $\gamma$-aminobuyrate by pyrroline dehydrogenase (Seiler et al., 1979; Fogel et al., 1981; Majumdar et al., 2013). Another compound related to polyamines is $S$-adenosylmethionine (SAM), which is essential for the synthesis of polyamines. $S$-adenosylmethionine synthetase (Sams; EC 2.5.1.6) catalyzes the biosynthesis of SAM from ATP and L-methionine (Tabor and Tabor, 1984). In S. cerevisiae, methionine regulates the expression of the two SAMS genes (SAMS1 and SAMS2) (Thomas et al., 1988); and in turn SAMS2 gene is subjected to the inositol-choline regulation given by the octameric sequence $5^{\prime}$-CATRTGAA- $3^{\prime}$ contained in its upstream promoter region (Kodaki et al., 2003). Genes encoding Sams are evolutionarily well conserved (Mautino et al., 1996). In S. pombe mutants, the absence of Sams affected cell growth, mating and sporulation, and by over-expressing the gene, growth of the cells became methionine-sensitive (Hilti et al., 2000).

$5^{\prime}$-Methylthioadenosine (MTA), is a product of SAM catabolism during polyamine biosynthesis (Heby, 1981). More than $98 \%$ of MTA in S. cerevisiae is a by product of SAM, originated from the polyamine biosynthetic pathway (Avila et al., 2004). MTA can affect gene expression, proliferation, differentiation and apoptosis, and these effects may be due to the inhibitory effect that intracellular accumulation of this nucleoside has over polyamine biosynthesis in vivo (Raina et al., 1982; Garcea et al., 1987); in addition in S. cerevisiae, MTA causes a specific inhibition of spermidine synthase (Chattopadhyay et al., 2006a).

Regard plants, SAM is the precursor of ethylene, hence polyamines, DNA methylation and ethylene share it as a common precursor (Pandey et al., 2000). Polyamines are precursors of many plant secondary metabolites such as nicotine and tropane alkaloids (Martin-Tanguy, 2001). Furthermore, plant polyamine metabolism is also connected with the production of nitric oxide and GABA [Reviewed by Alcazar et al. (2010)]. The regulation of polyamine biosynthesis, proline and cytokinins by abscisic acid as well as ethylene during UV-B stress and salt stress has been documented (Rakitin et al., 2009; Xue et al., 2009; Shevyakova et al., 2013).

\section{POLYAMINES AND STRESS TOLERANCE OF FUNGAL MUTANTS AFFECTED IN POLYAMINE METABOLISM TO DIFFERENT STRESS CONDITIONS}

The study of the stress response in fungal mutants affected in polyamine metabolism was started with S. cerevisiae, where the authors had in mind evidences indicating some roles of polyamines in the protection of the cell and cell components, and cell differentiation (Balasundaram et al., 1993; Chattopadhyay et al., 2006b; Watanabe et al., 2012). In general the ability to deal with stress is diminished in mutants affected in any of the genes encoding enzymes related with polyamine metabolism. $U$. maydis is a well studied system in this regard, proving to be an important model organism for understanding polyamine metabolism, especially since this phytopathogenic fungus lacks spermine (Valdes-Santiago et al., 2009).

In general, fungal spores are rather more resistant to different environmental stresses than vegetative cells. However, in the early steps of germination, when they loose their unique spore wall, they become more sensitive to different environmental stresses (Herman and Rine, 1997; Joseph-Strauss et al., 2007). Interestingly, it has been described that polyamines affect positively spore germination in Glomus mosseae, Rhizopus stolonifer, Botryodiplodia theobromae, Gigaspora rosea, and Glomus etunicatum (Nickerson et al., 1977; El Ghachtouli et al., 1996; Sannazzaro et al., 2004; Cheng et al., 2012). Inhibition of polyamine metabolism gave rise to an inhibition of spore germination and germ tube growth in fungi such as Uromyces phaseoli (Galston, 1989). Genes related with polyamine transport have been implicated in the germination process, and it was described that these genes are up-regulated compared to the vegetative state (Ruiz-Herrera, 1994; Dembek et al., 2013). These results suggest a relationship between polyamines and changes in the expression of 
genes related to stress. During a study of $S$. cerevisiae sporulationspecific genes, two divergently transcribed genes DIT1 and DIT2, were found to be repressed during vegetative growth via a common negative regulatory element, referred to as NER ${ }^{\mathrm{DIT}}$ (Friesen et al., 1997). The authors reported that the spermidine synthase gene was required for complete repression through $\mathrm{NER}^{\mathrm{DIT}}$, and cells that could not synthesize spermidine not only failed to support complete repression, but also had modest defects in repression of other genes, suggesting that spermidine could modulate gene expression (Friesen et al., 1998). However, there is not yet a report about gene expression response of fungi to different environmental stresses that reveal information on what is the mechanism through which polyamine are operating in this context.

\section{ROLE OF PHYSIOLOGICAL POLYAMINES ON OSMOTIC STRESS}

In silico phylogenetic analyses have revealed that central components of the osmotic, oxidative and cell wall stress signaling pathways are relatively well conserved in fungi (Bahn et al., 2007; Nikolaou et al., 2009). Nevertheless, knowing that polyamines are important in the response to stress, and that their metabolic pathway has been conserved among all living organism; we may suggest that a principal role of polyamines is to promote the restoration of cellular homeostasis allowing survival under stressful conditions. In S. cerevisiae, the expression of the major permease for high affinity polyamine import coincided with the osmotic stress imposed by high concentration of $\mathrm{NaCl}, \mathrm{KCl}$, or sorbitol (Lee et al., 2002; Aouida et al., 2005). Also in yeast, it was observed that the serine/threonine protein kinases Ptk1p and Ptk2p were involved in the regulation of spermine uptake, and that disruption of PTK2 gave rise to salt tolerance, while Ptk2p or Sky1p (another serine/threonine kinase that was found in spermine tolerant strains) over-expression, led to increased salt sensitivity (Erez and Kahana, 2001). These and other data clearly reveal that polyamines have a role in osmotic stress response, probably by regulation of the expression of osmotic stress signaling via protein kinases (Auvinen et al., 1992; Shore et al., 1997; Flamigni et al., 1999).

As would be expected, it is known that the lipid composition of the membrane affects the osmotic stability of the yeast plasma membrane (Allakhverdiev et al., 1999). In consequence, it was important to establish if the sensitivity of polyamine mutants to different kinds of stress was due to a defect at the membrane level or to an indirect alteration of other signaling pathways controlled by polyamines. In this sense, data exist showing that osmotic shock in different systems affects the intracellular levels of polyamines. For example, it was reported that under osmotic shock the content of putrescine was increased up to 60 -fold in oat, barley, corn, wheat, and wild oat leaves (Flores and Galston, 1982); and the induction of Odc activity under hypo-osmotic stress leading to an increase in the polyamine pool was observed in L1210 mouse leukemia cells (Poulin et al., 1991). The effect of a high osmotic concentration was tested in $U$. maydis mutants affected in the gene encoding spermidine synthase $(s p d)$, and in double mutants affected also in the ornithine decarboxylase gene $(o d c / s p d)$. Both simple and double mutants showed no significant differences in their growth rate in the absence of salt stress, when compared to the wild type, but growth rate of the same cells treated with $1 \mathrm{M} \mathrm{KCl}$ or $0.3 \mathrm{mM}$ SDS was severely inhibited in comparison with the wild type strain. This result demonstrates a role of spermidine in protecting the fungus from different deleterious factors that affect the cell membrane (Valdes-Santiago et al., 2009). When mutants affected in the polyamine oxidase gene ( $p a o)$, and double mutants affected in ornithine decarboxylase and polyamine oxidase (odc/pao) were subjected to ionic or osmotic stress ( $1 \mathrm{M} \mathrm{NaCl}, 10 \mathrm{mM} \mathrm{LiCl}$, or $1 \mathrm{M}$ sorbitol), only the double mutant displayed a sensitive phenotype, whereas the simple pao mutant showed no differences to the wild type strain (Valdes-Santiago et al., 2010).

To understand the effects of polyamine deficiency on the phenotypic alterations suffered by the cell subjected to osmotic stress, it is important to take into consideration the existence of specific mechanisms involved in cation handling, and the possible effect of some pathways that interact with polyamine metabolism. This fact was clearly demonstrated by the comparison of the behavior of $U$. maydis $S$-adenosylmethionine decarboxylase (samdc) and spd mutants under stress conditions. Growth rate of both mutants was substantially inhibited by $1 \mathrm{M} \mathrm{NaCl}$, but only the samdc mutant was affected by $10 \mathrm{mM} \mathrm{LiCl}$. A fundamental difference between samdc and spd mutant is that, unlike the wild-type strain, they accumulate high levels of SAM, but spd mutants also accumulate SAM. The other metabolite involved in the pathway is dcSAM, which was 46-fold increased in the spd mutants (ValdésSantiago et al., 2012b). The authors explained these differences in the phenotype in relation to their different levels of SAM and dcSAM, which could affect DNA methylation, and other different cellular functions, plus the possibility that sodium and lithium are managed by different transporters.

A further example of the specificity of polyamines in osmotic stress was the observation that in Synechocystis sp., a cyanobacterium, salt stress induced an increase in the spermine content, whereas an osmotic stress induced a moderate increase in the total spermidine content (Jantaro et al., 2003). Interestingly, this response was correlated with an increase of arginine decarboxylase mRNA levels, and an increase in the uptake of putrescine and spermidine (Incharoensakdi et al., 2010). In this sense, we may cite that simple or double $U$. maydis polyamine mutants presented a variety of stress sensitivities to osmotic stress (Figures 2B,D), compared with wild type and same mutants without stressful agent (Figure 2A).

In plants it has been well established that general polyamine biosynthesis is modified under salt stress at transcriptional level [for review see (Mutlu and Bozcuk, 2007; Liu et al., 2008; Alcazar et al., 2010; Gupta et al., 2013)]. However, spermine seems to have a specific role considering that, this is the polyamine reported to be more affected regardless of species, varieties and plant tissue studied. To mention some examples, plants such as A. thaliana unable to produce spermine showed hypersensitivity to high levels of $\mathrm{NaCl}$ and $\mathrm{KCl}$ and the mechanism behind polyamines protectection of salt stress has been studied. Some reports suggest that, polyamines improve ionic equilibrium by modifying the plasma membrane to overcome the osmotic stress since the expression of some genes belonging to signaling pathway related with salt stress were not altered in spermine deficient 


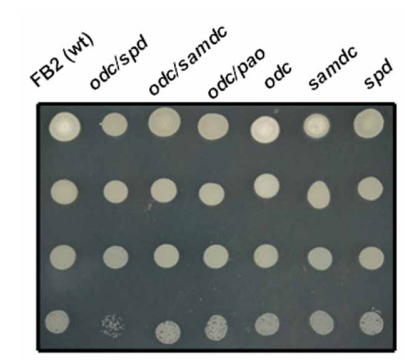

A

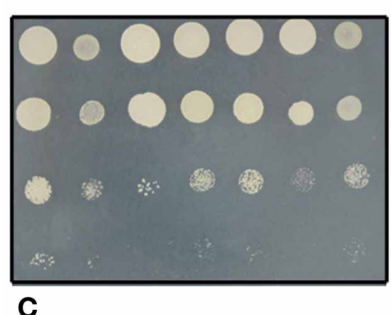

B
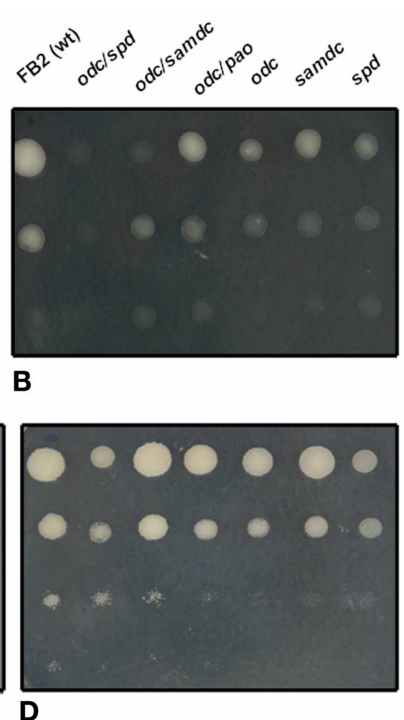

FIGURE 2 | Comparative analysis of different stress conditions on the growth of wild type, and simple and double mutants of $\boldsymbol{U}$. maydis affected in different steps of polyamine metabolism. After depletion of polyamine pools, cell suspensions were decimally diluted and inoculated on solid minimal medium containing $20 \mathrm{mM}$ lysine and $0.1 \mathrm{mM}$ spermidine. After $48 \mathrm{~h}$ of incubation at $28^{\circ} \mathrm{C}$ (except in C), photographs were taken. (A), control; (B), $1.5 \mathrm{M} \mathrm{KCl}$ added to the medium; (C), as (A), but incubated at $37^{\circ} \mathrm{C}$; (D), $1 \mathrm{M} \mathrm{NaCl}$ added to the medium.

mutant. Moreover, spermine seemed to modulate $\mathrm{Ca}^{2+}$ permeable channels and change $\mathrm{Ca}^{2+}$ allocation restraining the entry of $\mathrm{Na}^{+} / \mathrm{K}^{+}$to the cytoplasm (Yamaguchi et al., 2006; JanickaRussak et al., 2010; Najmeh et al., 2012; Velarde-Buendia et al., 2012). Other reports described that spermidine or putrescine are the polyamines conferring protection under salt stress, although it is difficult to support this conclusion, since putrescine or spermidine can be inter-converted (Quinet et al., 2010; Saleethong et al., 2011). In this respect, mutants are very effective in avoid confused results since they can define whether polyamines are produced by de novo synthesis or back-conversion (Valdes-Santiago et al., 2010).

\section{OXIDATIVE STRESS RESPONSE}

Fungi, as well as other microorganisms, must deal with the danger of oxidative stress under different scenarios. An important example is the oxidative killing of fungal cells by the host defense mechanisms, and sometimes the ability to proliferate in the host has been correlated with the expression of redox active enzymes such as catalase (Wysong et al., 1998; MoyeRowley, 2003). Accordingly, it has been concluded that one of the polyamine functions is the cell protection from damage caused by ROS (Rider et al., 2007; Cerrada-Gimenez et al., 2011). In the case of E. coli, oxidative stress induces the expression of catalase, hydroperoxide reductase and glutathione reductase (Storz and Imlay, 1999; Chattopadhyay et al., 2003a), and interestingly, putrescine is up-regulated the bacterium in a concentrationdependent manner with the expression level of the transcription factor controlling the genes already mentioned (Kim and Oh, 2000; Tkachenko et al., 2001). In the case of $U$. maydis it was observed that pao and odc polyamine mutants grown on agar plates where $0.8 \mathrm{mM} \mathrm{H}_{2} \mathrm{O}_{2}$-containg paper disks were placed, showed halos of inhibition wider in comparison with the wildtype strain; i.e., they were more sensitive than the wild type to the oxidative stress (Valdes-Santiago et al., 2010).

In fungi in general the mechanism regulating their response to oxidative stress has been described to involve the control of oxidant-responsive factors, such as Yap1p at level of cell localization and by regulation of enzyme activity via protein phosphorylation (Moye-Rowley, 2003). When S. cerevisiae was affected in the production of spermidine and spermine because of a deletion of the Samdc gene; there occurred a loss in cell viability when cultures were incubated under an oxygen atmosphere (Balasundaram et al., 1993).

It has also been shown that yeasts affected in the production of spermidine accumulate ROS, and show an increased sensitive to oxidative damage. In this regard, polyamine-deficiency in $S$. cerevisiae induced accumulation of ROS that led to the development of an apoptotic phenotype (Chattopadhyay et al., 2006b). These authors showed that one of the polyamine functions was the protection to the accumulation of ROS. There is yet to know whether polyamines act by affecting the enzymes involved in the synthesis or degradation of ROS, or by a direct interaction with ROS. Some evidences point out to some hypothetical polyaminebinding sites in proteins involved in these different processes (Watanabe et al., 2012). In this same respect, it has been proposed that spermine acts by direct scavenging of reactive agents (Ha et al., 1998; Fujisawa and Kadoma, 2005), whereas other authors have suggested an inhibition of the activity of NADPH oxidase (Papadakis and Roubelakis-Angelakis, 2005), and a role of polyamines as regulators of the MAPK signaling pathway (Stark et al., 2011).

In plants, a swift accumulation of ROS is presented under stressful conditions (Gill and Tuteja, 2010b; Suzuki et al., 2012); and it has been observed that intracellular ROS produced by polyamine catabolism are essential during development. Thus, it has been described that $\mathrm{H}_{2} \mathrm{O}_{2}$ generated during their oxidation and back-conversion serve as a signaling molecule correlated with plant defense and stress response (Moschou and RoubelakisAngelakis, 2011; Pottosin et al., 2012). Accordingly, in Salvinia natans response to salinity there occurs an interaction between ROS formation, and the expression of $A d c$, Samdc, Spd, and Spm as well as Pao (Tanou et al., 2013).

\section{TEMPERATURE STRESS}

Temperature has critical effects on microbial metabolism and cellular composition (Bennett et al., 1992; Feder and Hofmann, 1999; Fargues and Luz, 2000; Gavito and Azcon-Aguilar, 2012). It has been suggested that polyamines are involved in the stabilization of cellular components at high temperatures; for example a Tapesia yallundae odc null mutant exhibited temperature-dependent growth: at high temperatures, hyphal elongation was more restricted in comparison to the wild type, and the hyphae were thinner, less melanized, and grew sparsely (Mueller et al., 2001). Similarly, an S. cerevisiae mutant unable 
to synthesize spermidine or spermine, because it was affected in the gene encoding $S$-adenosylmethionine decarboxylase, was more sensitive to elevated temperatures than the parental strain (Balasundaram et al., 1996). The opposite takes place when polyamines are accumulated. Under these conditions, the cells present resistance to high temperature stress (Cheng et al., 2009). Simple and double $U$. maydis mutants affected in polyamine metabolism also presented a temperature sensitive phenotype in agreement with the reports above mentioned (see Figure 2C).

In plants, polyamine alterations have been correlated with temperature changes; under cold treatment putrescine levels were increased together with the expression of $A d c 1, A d c 2$, and Samdc2 in A. thaliana (Urano et al., 2003; Cuevas et al., 2008), while the addition of putrescine had a positive effect over cotton seed subjected to high temperature (Bibi et al., 2010). These results are in agreement with reports on Arabidopsis thaliana, where a mutant affected in the gene encoding spermine synthase was hypersensitive to heat shock; whereas an overexpression of spermine synthase-encoding gene conferred thermotolerance to the cell (Sagor et al., 2013). In the same study it was established a direct correlation between spermine content and the expression of heat shock genes and proteins suggesting that there is a control of polyamines at transcriptional and translational levels to induce the protection of plants under temperature stress. It is interesting to notice that although $U$. maydis does not contain spermine, spermidine covers the function to resist temperature stress (Figure 2C).

In the same line, it has been suggested that he mechanism behind the sensitivity of polyamine-deficient cells could be related to the stability that polyamines may provide to some cell components (Schuber, 1989).

\section{POLYAMINES IN STRESS PRODUCED BY PATHOGEN-HOST INTERACTIONS}

It is well known that during the course of host colonization, fungal pathogens need to overcome a wide range of challenges such as oxidative burst, which results in the production and accumulation of ROS. It has been proposed possible roles for polyamines and polyamine catabolism in plant resistance to pathogen infection (Walters, 2003). In this context, plants would activate polyamine oxidation to produce hydrogen peroxide, which would lead plant defense mechanisms. Yoda et al. (2003) confirmed these data, when they correlated hypersensitive response with the accumulation of polyamines in the apoplast of Arabidopsis thaliana infected with Pseudomonas syringae, and of rice infected with Magnaporthe grisea (Yoda et al., 2003). Expression of Odc, Adc, and Samdc genes in Theobroma cacao were induced under different stresses such as, drought and infection with Phytophthora megakarya, or the necrosis inducing protein Nep1 from Fusarium oxysporum while Spds and Sps were not changed (Bae et al., 2008). In the same manner, $\mathrm{H}_{2} \mathrm{O}_{2}$ produced by Paos during hypersensitive response provoke disease tolerance against Pseudomonas syringae $p v$ tabaci and Phytophthora parasitica var nicotianae (Yoda et al., 2003; Moschou et al., 2009).

Spermine has been proposed as the polyamine that contribute to defense signaling against plant pathogens through the regulation of defense-related genes. In this sense, an A. thaliana mutant that overexpressed Sps gene, displayed higher resistance to infection with Pseudomonas viridiflava, whereas a mutant with low spermine levels showed hyper sensitivity; interestingly the overexpression of Sps was accompanied by up-regulation of genes involved in disease resistance protein, as well as several transcription factors (Cona et al., 2006; Kusano et al., 2008; Gonzalez et al., 2011). Likewise, spermine-responsive genes were detected in A. thaliana during infection with cucumber mosaic virus, and interestingly, blocking of spermine oxidation abolished induction of these genes (Mitsuya et al., 2009). In general, response from pathogenic organism with distinct strategies to cause disease either necrotrophic or biotrophic, is essentially analogous, as was demonstrated with Sclerotinia sclerotiorium and compared with some Pseudomonas species or U. maydis (Marina et al., 2008; Rodriguez-Kessler et al., 2008; Rodriguez-Kessler and JimenezBremont, 2009). In these two cases what was observed was the induction of polyamines connected with the activation of genes encoding polyamine biosynthesis enzymes. Nevertheless, it is important to mention that changes in plant polyamine metabolism by transgenic strategies allow the modification of plant responses to pathogenic organisms. The expression of yeast Spe gene and accumulation of polyamine levels in tomato led to an increasing of sensitivity to the attack by Botrytis cinerea, but not by Alternatia solani and the normal response to the attack was restored by polyamine inhibitors (Marina et al., 2008; Nambeesan et al., 2012).

From the side of the pathogen, the state of polyamine metabolism affects their interaction with the host. When this Streptococcus pneumoniae was affected in polyamine transport, the mutant strain showed attenuation in virulence in a murine model. And it has been reported that human bacterial pathogens use different strategies related with polyamines to infect their hosts (Ware et al., 2006; Di Martino et al., 2013). A polyamine mutant of Salmonella enterica serovar typhimurium, was unable to invade and survive intracellularly in Caenorhabditis elegans, and showed no systemic infection in a mouse model of typhoid fever (Jelsbak et al., 2012). Francisella tularensis, Yersinia pestis and Vibrio cholerae are other systems in which synthesis and transport of polyamines were found to be important for virulence (Wortham et al., 2010; Russo et al., 2011; Goforth et al., 2013). Regarding fungi, a spe mutant of the thermally dimorphic fungus Penicillium marneffei, a pathogen of immune compromised persons, showed defects in pathogenesis, conidiogenesis, spore germination, and growth. These results led to suggest that the spermidine biosynthetic may serve as a potential target for combating infections (Kummasook et al., 2013). Agreeing with these ideas, in another pathosytem reviewed by Valdés-Santiago et al. (2012b): U.maydis-maize, it was observed that samdc mutants of the fungus were avirulent.

\section{GENERAL CONCLUSIONS AND FUTURE PERSPECTIVES}

Along this article, evidences indicate multiple roles of polyamines in cell survival during stress. A strategy toward the knowing of the mechanism behind polyamines action should include firstly the clear identification of the specific roles of each polyamine i. e., in $U$. maydis putrescine might be controlling stress response since the mutant (odc/pao) was over sensitive to stress, in comparison 
to the wild type and and pao mutant. Also, spermidine appeared to control differentiation of this fungus, since mutant it was able to carry out a dimorphic transition only when supplied with high concentration of spermidine (Valdes-Santiago et al., 2010). Once the specific roles of each polyamine are known, it will be possible to distinguish the role of other polyamines in the general aspect of cell physiology. This review clearly stresses the fact that changes in polyamine metabolism affect the response of fungi to different types of stress. This fact by itself is an evidence of the importance of polyamines in cell survival.

Although a large advance in our understanding on polyamine metabolism in fungi has taken place in recent years, some aspects are still poorly understood, especially regarding polyamine transport, distribution in the cell, and regulation of metabolism. It is also clear that the role of polyamines in stress-response mechanisms in fungi, and their mode of action have been insufficiently analyzed. We consider that it is necessary to have a global view of the physiology of stress response in fungi that includes polyamines as an important player, possibly using mutants affected in different steps of polyamine metabolism and its regulation, and studies of the relationships of polyamine metabolism with other important metabolic and regulatory processes of the cell. If this expectancy is fulfilled, undoubtedly that fungi will become important models that could help to unravel the mechanism of the protection exerted by polyamines to stress in general.

\section{ACKNOWLEDGMENTS}

The work by the authors reported here was partially supported by Consejo Nacional de Ciencia y Tecnología (CONACYT), México. José Ruiz-Herrera is emeritus investigator, México.

\section{REFERENCES}

Alcazar, R., Altabella, T., Marco, F., Bortolotti, C., Reymond, M., Koncz, C., et al. (2010). Polyamines: molecules with regulatory functions in plant abiotic stress tolerance. Planta 231, 1237-1249. doi: 10.1007/s00425-010-1130-0

Alcazar, R., Marco, F., Cuevas, J. C., Patron, M., Ferrando, A., Carrasco, P., et al. (2006). Involvement of polyamines in plant response to abiotic stress. Biotechnol. Lett. 28, 1867-1876. doi: 10.1007/s10529-006-9179-3

Allakhverdiev, S. I., Nishiyama, Y., Suzuki, I., Tasaka, Y., and Murata, N. (1999). Genetic engineering of the unsaturation of fatty acids in membrane lipids alters the tolerance of Synechocystis to salt stress. Proc. Natl. Acad. Sci. U.S.A. 96, 5862-5867. doi: 10.1073/pnas.96.10.5862

Aouida, M., Leduc, A., Poulin, R., and Ramotar, D. (2005). AGP2 encodes the major permease for high affinity polyamine import in Saccharomyces cerevisiae. J. Biol. Chem. 280, 24267-24276. doi: 10.1074/jbc.M503071200

Auvinen, M., Paasinen, A., Andersson, L. C., and Holtta, E. (1992). Ornithine decarboxylase activity is critical for cell transformation. Nature 360, 355-358. doi: 10.1038/360355a0

Avila, M. A., Garcia-Trevijano, E. R., Lu, S. C., Corrales, F. J., and Mato, J. M. (2004). Methylthioadenosine. Int. J. Biochem. Cell Biol. 36, 2125-2130. doi: 10.1016/j.biocel.2003.11.016

Bae, H., Kim, S. H., Kim, M. S., Sicher, R. C., Lary, D., Strem, M. D., et al. (2008). The drought response of Theobroma cacao (cacao) and the regulation of genes involved in polyamine biosynthesis by drought and other stresses. Plant Physiol. Biochem. 46, 174-188. doi: 10.1016/j.plaphy.2007.10.014

Bahn, Y. S., Xue, C., Idnurm, A., Rutherford, J. C., Heitman, J., and Cardenas, M. E. (2007). Sensing the environment: lessons from fungi. Nat. Rev. Microbiol. 5, 57-69. doi: 10.1038/nrmicro1578

Balasundaram, D., Tabor, C. W., and Tabor, H. (1993). Oxygen toxicity in a polyamine-depleted spe2 delta mutant of Saccharomyces cerevisiae. Proc. Natl. Acad. Sci. U.S.A. 90, 4693-4697. doi: 10.1073/pnas.90.10.4693
Balasundaram, D., Tabor, C. W., and Tabor, H. (1996). Sensitivity of polyamine-deficient Saccharomyces cerevisiae to elevated temperatures. J. Bacteriol. 178, 2721-2724.

Barnett, G. R., Seyfzadeh, M., and Davis, R. H. (1988). Putrescine and spermidine control degradation and synthesis of ornithine decarboxylase in Neurospora crassa. J. Biol. Chem. 263, 10005-10008.

Bennett, A. F., Lenski, R. E., and Mittler, J. E. (1992). Evolutionary adaptation to temperature. I. fitness responses of escherichia coli to changes in its thermal environment. Evolution 46, 16-30. doi: 10.2307/2409801

Bibi, A. C., Oosterhuis, D. M., and Gonias, E. D. (2010). Exogenous application of putrescine ameliorates the effect of high temperature in Gossypium hirsutum L. flowers and fruit development. J. Agron. Crop Sci. 196, 205-211. doi: 10.1111/j.1439-037X.2009.00414.x

Cerrada-Gimenez, M., Pietila, M., Loimas, S., Pirinen, E., Hyvonen, M. T., Keinanen, T. A., et al. (2011). Continuous oxidative stress due to activation of polyamine catabolism accelerates aging and protects against hepatotoxic insults. Transgenic Res. 20, 387-396. doi: 10.1007/s11248-010-9422-5

Chattopadhyay, M. K., Tabor, C. W., and Tabor, H. (2003a). Polyamines protect Escherichia coli cells from the toxic effect of oxygen. Proc. Natl. Acad. Sci. U.S.A. 100, 2261-2265. doi: 10.1073/pnas.2627990100

Chattopadhyay, M. K., Tabor, C. W., and Tabor, H. (2003b). Spermidine but not spermine is essential for hypusine biosynthesis and growth in Saccharomyces cerevisiae: spermine is converted to spermidine in vivo by the FMS1-amine oxidase. Proc. Natl. Acad. Sci. U.S.A. 100, 13869-13874. doi: 10.1073/pnas.1835918100

Chattopadhyay, M. K., Tabor, C. W., and Tabor, H. (2006a). Methylthioadenosine and polyamine biosynthesis in a Saccharomyces cerevisiae meuldelta mutant. Biochem. Biophys. Res. Commun. 343, 203-207. doi: 10.1016/j.bbrc.2006.02.144

Chattopadhyay, M. K., Tabor, C. W., and Tabor, H. (2006b). Polyamine deficiency leads to accumulation of reactive oxygen species in a spe2Delta mutant of Saccharomyces cerevisiae. Yeast 23, 751-761. doi: 10.1002/yea.1393

Cheng, L., Zou, Y., Ding, S., Zhang, J., Yu, X., Cao, J., et al. (2009). Polyamine accumulation in transgenic tomato enhances the tolerance to high temperature stress. J. Integr. Plant Biol. 51, 489-499. doi: 10.1111/j.1744-7909.2009. 00816.x

Cheng, Y., Ma, W., Li, X., Miao, W., Zheng, L., and Cheng, B. (2012). Polyamines stimulate hyphal branching and infection in the early stage of Glomus etunicatum colonization. World J. Microbiol. Biotechnol. 28, 1615-1621. doi: 10.1007/s11274-011-0967-0

Coffino, P. (2001a). Antizyme, a mediator of ubiquitin-independent proteasomal degradation. Biochimie 83, 319-323. doi: 10.1016/S0300-9084(01)01252-4

Coffino, P. (2001b). Regulation of cellular polyamines by antizyme. Nat. Rev. Mol. Cell Biol. 2, 188-194. doi: 10.1038/35056508

Cona, A., Rea, G., Botta, M., Corelli, F., Federico, R., and Angelini, R. (2006). Flavin-containing polyamine oxidase is a hydrogen peroxide source in the oxidative response to the protein phosphatase inhibitor cantharidin in Zea mays. J. Exp. Bot. 57, 2277-2289. doi: 10.1093/jxb/erj195

Cuevas, J. C., Lopez-Cobollo, R., Alcazar, R., Zarza, X., Koncz, C., Altabella, T., et al. (2008). Putrescine is involved in arabidopsis freezing tolerance and cold acclimation by regulating abscisic acid levels in response to low temperature. Plant Physiol. 148, 1094-1105. doi: 10.1104/pp.108.122945

Dembek, M., Stabler, R. A., Witney, A. A., Wren, B. W., and Fairweather, N. F. (2013). Transcriptional analysis of temporal gene expression in germinating Clostridium difficile 630 endospores. PLOS ONE 8:e64011. doi: 10.1371/journal.pone.0064011

Di Martino, M. L., Campilongo, R., Casalino, M., Micheli, G., Colonna, B., and Prosseda, G. (2013). Polyamines: emerging players in bacteria-host interactions. Int. J. Med. Microbiol. 303, 484-491. doi: 10.1016/j.ijmm.2013.06.008

El Ghachtouli, N., Paynot, M., Martin-Tanguy, J., Morandi, D., and Gianinazzi, S. (1996). Effect of polyamines and polyamine biosynthesis inhibitors on spore germination and hyphal growth of Glomus mosseae. Mycol. Res. 100, 597-600. doi: 10.1016/S0953-7562(96)80014-1

Erez, O., and Kahana, C. (2001). Screening for modulators of spermine tolerance identifies Sky1, the SR protein kinase of Saccharomyces cerevisiae, as a regulator of polyamine transport and ion homeostasis. Mol. Cell. Biol. 21, 175-184. doi: 10.1128/MCB.21.1.175-184.2001

Fargues, J., and Luz, C. (2000). Effects of fluctuating moisture and temperature regimes on the infection potential of Beauveria bassiana for Rhodnius prolixus. J. Invertebr. Pathol. 75, 202-211. doi: 10.1006/jipa.1999.4923 
Feder, M. E., and Hofmann, G. E. (1999). Heat-shock proteins, molecular chaperones, and the stress response: evolutionary and ecological physiology. Annu. Rev. Physiol. 61, 243-282. doi: 10.1146/annurev.physiol.61.1.243

Flamigni, F., Facchini, A., Capanni, C., Stefanelli, C., Tantini, B., and Caldarera, C. M. (1999). p44/42 mitogen-activated protein kinase is involved in the expression of ornithine decarboxylase in leukaemia L1210 cells. Biochem. J. 341( $\mathrm{Pt} 2)$, 363-369. doi: 10.1042/0264-6021:3410363

Flores, H. E., and Galston, A. W. (1982). Polyamines and plant stress: activation of putrescine biosynthesis by osmotic shock. Science 217, 1259-1261. doi: 10.1126/science.217.4566.1259

Fogel, W. A., Bieganski, T., Schayer, R. W., and Maslinski, C. (1981). Involvement of diamine oxidase in catabolism of $14 \mathrm{C}$-putrescine in mice in vivo with special reference to the formation of gamma-aminobutyric acid. Agents Actions 11, 679-684. doi: 10.1007/BF01978789

Friesen, H., Hepworth, S. R., and Segall, J. (1997). An Ssn6-Tup1-dependent negative regulatory element controls sporulation-specific expression of DIT1 and DIT2 in Saccharomyces cerevisiae. Mol. Cell. Biol. 17, 123-134.

Friesen, H., Tanny, J. C., and Segall, J. (1998). Spe3, which encodes spermidine synthase, is required for full repression through NRE(DIT) in Saccharomyces cerevisiae. Genetics 150, 59-73.

Fuell, C., Elliott, K. A., Hanfrey, C. C., Franceschetti, M., and Michael, A. J. (2010). Polyamine biosynthetic diversity in plants and algae. Plant Physiol. Biochem. 48, 513-520. doi: 10.1016/j.plaphy.2010.02.008

Fujisawa, S., and Kadoma, Y. (2005). Kinetic evaluation of polyamines as radical scavengers. Anticancer Res. 25, 965-969.

Galston, A. W. (1989). Inhibition of uredospore germination and germ tube growth by inhibitors of polyamine metabolism in Uromyces phaseoli L. Plant Cell Physiol. 30, 37-41.

Galston, A. W., and Sawhney, R. K. (1990). Polyamines in plant physiology. Plant Physiol. 94, 406-410. doi: 10.1104/pp.94.2.406

Gandre, S., and Kahana, C. (2002). Degradation of ornithine decarboxylase in Saccharomyces cerevisiae is ubiquitin independent. Biochem. Biophys. Res. Commun. 293, 139-144. doi: 10.1016/S0006-291X(02)00194-8

Garcea, R., Pascale, R., Daino, L., Frassetto, S., Cozzolino, P., Ruggiu, M. E., et al. (1987). Variations of ornithine decarboxylase activity and S-adenosylL-methionine and $5^{\prime}$-methylthioadenosine contents during the development of diethylnitrosamine-induced liver hyperplastic nodules and hepatocellular carcinoma. Carcinogenesis 8, 653-658. doi: 10.1093/carcin/8.5.653

Gasch, A. P. (2007). Comparative genomics of the environmental stress response in ascomycete fungi. Yeast 24, 961-976. doi: 10.1002/yea.1512

Gavito, M. E., and Azcon-Aguilar, C. (2012). Temperature stress in arbuscular mycorrhizal fungi: a test for adaptation to soil temperature in three isolates of Funneliformis mosseae from different climates. Agric. Food Sci. 21, 2-11.

Ge, C., Cui, X., Wang, Y., Hu, Y., Fu, Z., Zhang, D., et al. (2006). BUD2, encoding an $S$-adenosylmethionine decarboxylase, is required for Arabidopsis growth and development. Cell Res. 15, 446-456. doi: 10.1038/sj.cr.7310056

Giaever, G., Chu, A. M., Ni, L., Connelly, C., Riles, L., Veronneau, S., et al. (2002). Functional profiling of the Saccharomyces cerevisiae genome. Nature 418, 387-391. doi: 10.1038/nature00935

Gill, S. S., and Tuteja, N. (2010a). Polyamines and abiotic stress tolerance in plants. Plant Signal. Behav. 5, 26-33. doi: 10.4161/psb.5.1.10291

Gill, S. S., and Tuteja, N. (2010b). Reactive oxygen species and antioxidant machinery in abiotic stress tolerance in crop plants. Plant Physiol. Biochem. 48, 909-930. doi: 10.1016/j.plaphy.2010.08.016

Goforth, J. B., Walter, N. E., and Karatan, E. (2013). Effects of polyamines on Vibrio cholerae virulence properties. PLoS ONE 8:e60765. doi: 10.1371/journal.pone.0060765

Gonzalez, M. E., Marco, F., Minguet, E. G., Carrasco-Sorli, P., Blazquez, M. A., Carbonell, J., et al. (2011). Perturbation of spermine synthase gene expression and transcript profiling provide new insights on the role of the tetraamine spermine in Arabidopsis defense against Pseudomonas viridiflava. Plant Physiol. 156 2266-2277. doi: 10.1104/pp.110.171413

Gupta, K., Dey, A., and Gupta, B. (2013). Plant polyamines in abiotic stress responses. Acta Physiol. Plant. 35, 2015-2036. doi: 10.1007/s11738-0131239-4

Ha, H. C., Yager, J. D., Woster, P. A., and Casero, R. A. Jr. (1998). Structural specificity of polyamines and polyamine analogues in the protection of DNA from strand breaks induced by reactive oxygen species. Biochem. Biophys. Res. Commun. 244, 298-303. doi: 10.1006/bbrc.1998.8258
Hayashi, S., Murakami, Y., and Matsufuji, S. (1996). Ornithine decarboxylase antizyme: a novel type of regulatory protein. Trends Biochem. Sci. 21, 27-30. doi: 10.1016/0968-0004(96)80882-6

Heby, O. (1981). Role of polyamines in the control of cell proliferation and differentiation. Differentiation 19, 1-20. doi: 10.1111/j.1432-0436.1981.tb01123.x

Herman, P. K., and Rine, J. (1997). Yeast spore germination: a requirement for Ras protein activity during re-entry into the cell cycle. EMBO J. 16, 6171-6181. doi: 10.1093/emboj/16.20.6171

Hilti, N., Graub, R., Jorg, M., Arnold, P., Schweingruber, A. M., and Schweingruber, M. E. (2000). Gene saml encoding adenosylmethionine synthetase: effects of its expression in the fission yeast Schizosaccharomyces pombe. Yeast 16, 1-10. doi: 10.1002/(SICI)1097-0061(20000115)16:1<1::AID-YEA501>3. 3.CO;2-B

Hoyt, M. A., Broun, M., and Davis, R. H. (2000). Polyamine regulation of ornithine decarboxylase synthesis in Neurospora crassa. Mol. Cell. Biol. 20, 2760-2773. doi: 10.1128/MCB.20.8.2760-2773.2000

Hu, W. W., Gong, H., and Pua, E. C. (2005). The pivotal roles of the plant $S$-adenosylmethionine decarboxylase $5^{\prime}$ untranslated leader sequence in regulation of gene expression at the transcriptional and posttranscriptional levels. Plant Physiol. 138, 276-286. doi: 10.1104/pp.104.056770

Illingworth, C., and Michael, A. J. (2012). Plant ornithine decarboxylase is not post-transcriptionally feedback regulated by polyamines but can interact with a cytosolic ribosomal protein S15 polypeptide. Amino Acids 42, 519-527. doi: 10.1007/s00726-011-1029-5

Imai, A., Matsuyama, T., Hanzawa, Y., Akiyama, K., Tamaoki, M., Saji, H., et al. (2004). Spermidine synthase genes are essential for survival of Arabidopsis. Plant Physiol. 135, 1565-1573. doi: 10.1104/pp.104.041699

Incharoensakdi, A., Jantaro, S., Raksajit, W., and Mäenpää, P. (2010). "Polyamines in cyanobacteria: biosynthesis, transport and abiotic stress response," in Current Research, Technology and Education Topics in Applied Microbiology and Microbial Biotechnology, ed A. Méndez-Vilas (Spain: Formatex), 23-32.

Ivanov, I. P., and Atkins, J. F. (2007). Ribosomal frameshifting in decoding antizyme mRNAs from yeast and protists to humans: close to 300 cases reveal remarkable diversity despite underlying conservation. Nucleic Acids Res. 35, 1842-1858. doi: 10.1093/nar/gkm035

Ivanov, I. P., Gesteland, R. F., and Atkins, J. F. (2006). Evolutionary specialization of recoding: frameshifting in the expression of S. cerevisiae antizyme mRNA is via an atypical antizyme shift site but is still +1. RNA 12, 332-337. doi: 10.1261/rna.2245906

Janicka-Russak, M., Kabala, K., Mlodzinska, E., and Klobus, G. (2010). The role of polyamines in the regulation of the plasma membrane and the tonoplast proton pumps under salt stress. J. Plant Physiol. 167, 261-269. doi: 10.1016/j.jplph.2009.09.010

Jantaro, S., Maenpaa, P., Mulo, P., and Incharoensakdi, A. (2003). Content and biosynthesis of polyamines in salt and osmotically stressed cells of Synechocystis sp. PCC 6803. FEMS Microbiol. Lett. 228, 129-135. doi: 10.1016/S03781097(03)00747-X

Jelsbak, L., Thomsen, L. E., Wallrodt, I., Jensen, P. R., and Olsen, J. E. (2012). Polyamines are required for virulence in Salmonella enterica serovar Typhimurium. PLoS ONE 7:e36149. doi: 10.1371/journal.pone.0036149

Joseph-Strauss, D., Zenvirth, D., Simchen, G., and Barkai, N. (2007). Spore germination in Saccharomyces cerevisiae: global gene expression patterns and cell cycle landmarks. Genome Biol. 8:R241. doi: 10.1186/gb-2007-8-11-r241

Khan, A. J., and Minocha, S. C. (1989). Biosynthetic arginine decarboxylase in phytopathogenic fungi. Life Sci. 44, 1215-1222. doi: 10.1016/0024-3205(89)90317-2

Kim, I. G., and Oh, T. J. (2000). SOS induction of the recA gene by UV-, gammairradiation and mitomycin $\mathrm{C}$ is mediated by polyamines in Escherichia coli K12. Toxicol. Lett. 116, 143-149. doi: 10.1016/S0378-4274(00)00215-0

Kodaki, T., Tsuji, S., Otani, N., Yamamoto, D., Rao, K. S., Watanabe, S., et al. (2003). Differential transcriptional regulation of two distinct $S$-adenosylmethionine synthetase genes (SAM1 and SAM2) of Saccharomyces cerevisiae. Nucleic Acids Res. Suppl. 303-304. doi: 10.1093/nass/3.1.303

Kummasook, A., Cooper, C. R. Jr., Sakamoto, A., Terui, Y., Kashiwagi, K., and Vanittanakom, N. (2013). Spermidine is required for morphogenesis in the human pathogenic fungus, Penicillium marneffei. Fungal Genet. Biol. 58-59: 25-32. doi: 10.1016/j.fgb.2013.08.001

Kurian, L., Palanimurugan, R., Godderz, D., and Dohmen, R. J. (2011). Polyamine sensing by nascent ornithine decarboxylase antizyme stimulates decoding of its mRNA. Nature 477, 490-494. doi: 10.1038/nature10393 
Kusano, T., Berberich, T., Tateda, C., and Takahashi, Y. (2008). Polyamines: essential factors for growth and survival. Planta 228, 367-381. doi: 10.1007/s00425-0080772-7

Landry, J., and Sternglanz, R. (2003). Yeast Fms1 is a FAD-utilizing polyamine oxidase. Biochem. Biophys. Res. Commun. 303, 771-776. doi: 10.1016/S0006291X(03)00416-9

Lee, J., Lee, B., Shin, D., Kwak, S. S., Bahk, J. D., Lim, C. O., et al. (2002). Carnitine uptake by AGP2 in yeast Saccharomyces cerevisiae is dependent on Hog1 MAP kinase pathway. Mol. Cells 13, 407-412.

Leon-Ramirez, C. G., Valdes-Santiago, L., Campos-Gongora, E., Ortiz-Castellanos, L., Arechiga-Carvajal, E. T., and Ruiz-Herrera, J. (2010). A molecular probe for Basidiomycota: the spermidine synthase-saccharopine dehydrogenase chimeric gene. FEMS Microbiol. Lett. 312, 77-83. doi: 10.1111/j.1574-6968.2010.02099.x

Liu, B., Sutton, A., and Sternglanz, R. (2005). A yeast polyamine acetyltransferase. J. Biol. Chem. 280, 16659-16664. doi: 10.1074/jbc.M414008200

Liu, J. H., Inoue, H., and Moriguchi, T. (2008). Salt stress-mediated changes in free polyamine titers and expression of genes responsible for polyamine biosynthesis of apple in vitro shoots. Environ. Exp. Bot. 62, 28-35. doi: 10.1016/j.envexpbot.2007.07.002

Lushchak, V. I. (2011). Adaptive response to oxidative stress: bacteria, fungi, plants and animals. Comp. Biochem. Physiol. C Toxicol. Pharmacol. 153, 175-190. doi: 10.1016/j.cbpc.2010.10.004

Majumdar, R., Shao, L., Minocha, R., Long, S., and Minocha, S. C. (2013). Ornithine: the overlooked molecule in the regulation of polyamine metabolism3. Plant Cell Physiol. 54, 990-1004. doi: 10.1093/pcp/pct053

Manni, A., Badger, B., Wright, C., Ahmed, S. R., Santner, S. J., and Luk, G. (1987). Role of polyamines in the synthesis of prolactin-regulated growth factors by experimental breast cancer in culture. Breast Cancer Res. Treat. 10, 191-196. doi: 10.1007/BF01810582

Marina, M., Maiale, S. J., Rossi, F. R., Romero, M. F., Rivas, E. I., Garriz, A., et al. (2008). Apoplastic polyamine oxidation plays different roles in local responses of tobacco to infection by the necrotrophic fungus Sclerotinia sclerotiorum and the biotrophic bacterium Pseudomonas viridiflava. Plant Physiol. 147, 2164-2178. doi: 10.1104/pp.108.122614

Martin-Tanguy, J. (2001). Metabolism and function of polyamines in plants: recent development (new approaches). Plant Growth Regul. 34, 135-148. doi: 10.1023/A:1013343106574

Mautino, M. R., Barra, J. L., and Rosa, A. L. (1996). eth-1, the Neurospora crassa locus encoding $S$-adenosylmethionine synthetase: molecular cloning, sequence analysis and in vivo overexpression. Genetics 142, 789-800.

Mitsuya, Y., Takahashi, Y., Berberich, T., Miyazaki, A., Matsumura, H., Takahashi, H., et al. (2009). Spermine signaling plays a significant role in the defense response of Arabidopsis thaliana to cucumber mosaic virus. J. Plant Physiol. 166 626-643. doi: 10.1016/j.jplph.2008.08.006

Montibus, M., Pinson-Gadais, L., Richard-Forget, F., Barreau, C., and Ponts N. (2013). Coupling of transcriptional response to oxidative stress and secondary metabolism regulation in filamentous fungi. Crit. Rev. Microbiol. doi: 10.3109/1040841X.2013.829416. [Epub ahead of print]

Moschou, P. N., and Roubelakis-Angelakis, K. A. (2011). Characterization, assay, and substrate specificity of plant polyamine oxidases. Methods Mol. Biol. 720 183-194. doi: 10.1007/978-1-61779-034-8 11

Moschou, P. N., Sarris, P. F., Skandalis, N., Andriopoulou, A. H., Paschalidis, K. A., Panopoulos, N. J., et al. (2009). Engineered polyamine catabolism preinduces tolerance of tobacco to bacteria and oomycetes. Plant Physiol. 149, 1970-1981. doi: $10.1104 / p p .108 .134932$

Moye-Rowley, W. S. (2003). Regulation of the transcriptional response to oxidative stress in fungi: similarities and differences. Eukaryot Cell 2, 381-389. doi: 10.1128/EC.2.3.381-389.2003

Mueller, E., Bailey, A., Corran, A., Michael, A. J., and Bowyer, P. (2001). Ornithine decarboxylase knockout in Tapesia yallundae abolishes infection plaque formation in vitro but does not reduce virulence toward wheat. Mol. Plant Microbe Interact. 14, 1303-1311. doi: 10.1094/MPMI.2001.14.11.1303

Mutlu, F., and Bozcuk, S. (2007). Salinity- induced changes of free and bound polyamine levels in sunflower (Helianthus Annuus L.) roots differing in salt tolerance. Pak J. Bot 39, 1097-1102.

Najmeh, N., Ehsan, S., and Ghorbanali, N. (2012). Salt-induced reduction in shoot spermine pool of Aeluropus littoralis. Adv. Environ. Biol. 6, 1765-1768.

Nambeesan, S., Abuqamar, S., Laluk, K., Mattoo, A. K., Mickelbart, M. V., Ferruzzi, M. G., et al. (2012). Polyamines attenuate ethylene-mediated defense responses to abrogate resistance to Botrytis cinerea in tomato. Plant Physiol. 158 , 1034-1045. doi: 10.1104/pp.111.188698

Nickerson, K. W., Dunkle, L. D., and Van Etten, J. L. (1977). Absence of spermine in filamentous fungi. J. Bacteriol. 129, 173-176.

Nikolaou, E., Agrafioti, I., Stumpf, M., Quinn, J., Stansfield, I., and Brown, A. J. (2009). Phylogenetic diversity of stress signalling pathways in fungi. BMC Evol. Biol. 9:44. doi: 10.1186/1471-2148-9-44

Ono, Y., Kim, D. W., Watanabe, K., Sasaki, A., Niitsu, M., Berberich, T., et al. (2012). Constitutively and highly expressed Oryza sativa polyamine oxidases localize in peroxisomes and catalyze polyamine back conversion. Amino Acids 42, 867-876. doi: 10.1007/s00726-011-1002-3

Pandey, S., Ranade, S. A., Nagar, P. K., and Kumar, N. (2000). Role of polyamines and ethylene as modulators of plant senescence. J. Biosci. 25, 291-299. doi: 10.1007/BF02703938

Papadakis, A. K., and Roubelakis-Angelakis, K. A. (2005). Polyamines inhibit NADPH oxidase-mediated superoxide generation and putrescine prevents programmed cell death induced by polyamine oxidase-generated hydrogen peroxide. Planta 220, 826-837. doi: 10.1007/s00425-004-1400-9

Pegg, A. E., and Michael, A. J. (2010). Spermine synthase. Cell. Mol. Life Sci. 67, 113-121. doi: 10.1007/s00018-009-0165-5

Pegg, A. E., Xiong, H., Feith, D. J., and Shantz, L. M. (1998). S-adenosylmethionine decarboxylase: structure, function and regulation by polyamines. Biochem. Soc. Trans. 26, 580-586.

Perez-Amador, M. A., Leon, J., Green, P. J., and Carbonell, J. (2002). Induction of the arginine decarboxylase ADC2 gene provides evidence for the involvement of polyamines in the wound response in Arabidopsis. Plant Physiol. 130, 1454-1463. doi: 10.1104/pp.009951

Pottosin, I., Velarde-Buendia, A. M., Zepeda-Jazo, I., Dobrovinskaya, O., and Shabala, S. (2012). Synergism between polyamines and ROS in the induction of $\mathrm{Ca}(2+)$ and $\mathrm{K}(+)$ fluxes in roots. Plant Signal. Behav. 7, 1084-1087. doi: $10.4161 / \mathrm{psb} .21185$

Poulin, R., Wechter, R. S., and Pegg, A. E. (1991). An early enlargement of the putrescine pool is required for growth in L1210 mouse leukemia cells under hypoosmotic stress. J. Biol. Chem. 266, 6142-6151.

Quinet, M., Ndayiragije, A., Lefevre, I., Lambillotte, B., Dupont-Gillain, C. C., and Lutts, S. (2010). Putrescine differently influences the effect of salt stress on polyamine metabolism and ethylene synthesis in rice cultivars differing in salt resistance. J. Exp. Bot. 61, 2719-2733. doi: 10.1093/jxb/erq118

Raina, A., Tuomi, K., and Pajula, R. L. (1982). Inhibition of the synthesis of polyamines and macromolecules by $5^{\prime}$-methylthioadenosine and $5^{\prime}$ alkylthiotubercidins in BHK21 cells. Biochem. J. 204, 697-703.

Rakitin, V. Y., Prudnikova, O. N., Rakitina, T. Y., Karyagin, V. V., Vlasov, P. V., Novikova, G. V., et al. (2009). Interaction between ethylene and ABA in the regulation of polyamine level in Arabidopsis thaliana during UV-B stress. Russ. J. Plant Physiol. 56, 147-153. doi: 10.1134/S1021443709020010

Rider, J. E., Hacker, A., Mackintosh, C. A., Pegg, A. E., Woster, P. M., and Casero, R. A. Jr. (2007). Spermine and spermidine mediate protection against oxidative damage caused by hydrogen peroxide. Amino Acids 33, 231-240. doi: 10.1007/s00726-007-0513-4

Rodriguez-Kessler, M., and Jimenez-Bremont, J. F. (2009). Ustilago maydis induced accumulation of putrescine in maize leaves. Plant Signal. Behav. 4, 310-312. doi: 10.4161/psb.4.4.8089

Rodriguez-Kessler, M., Ruiz, O. A., Maiale, S., Ruiz-Herrera, J., and Jimenez-Bremont, J. F. (2008). Polyamine metabolism in maize tumors induced by Ustilago maydis. Plant Physiol. Biochem. 46, 805-814. doi: 10.1016/j.plaphy.2008.05.012

Ruiz-Herrera, J. (1994). Polyamines, DNA methylation, and fungal differentiation. Crit. Rev. Microbiol. 20, 143-150. doi: 10.3109/10408419409113553

Russo, B. C., Horzempa, J., O’Dee, D. M., Schmitt, D. M., Brown, M. J., Carlson, P. E., et al. (2011). A Francisella tularensis locus required for spermine responsiveness is necessary for virulence. Infect. Immun. 79, 3665-3676. doi: 10.1128/IAI.00135-11

Sagor, G. H., Berberich, T., Takahashi, Y., Niitsu, M., and Kusano, T. (2013). The polyamine spermine protects Arabidopsis from heat stress-induced damage by increasing expression of heat shock-related genes. Transgenic Res. 22, 595-605. doi: $10.1007 / \mathrm{s} 11248-012-9666-3$

Saleethong, P., Sanitchon, J., Kong-Ngern, K., and Theerakulpisut, P. (2011). Pretreatment with spermidine reverses inhibitory effects of salt stress in two 
rice (Oryza sativa L.) cultivars differing in salinity tolerance. Asian J. Plant Sci. 10, 245-254. doi: 10.3923/ajps.2011.245.254

Sannazzaro, A. I., Alvarez, C. L., Menendez, A. B., Pieckenstain, F. L., Alberto, E. O., and Ruiz, O. A. (2004). Ornithine and arginine decarboxylase activities and effect of some polyamine biosynthesis inhibitors on Gigaspora rosea germinating spores. FEMS Microbiol. Lett. 230, 115-121. doi: 10.1016/S03781097(03)00880-2

Schuber, F. (1989). Influence of polyamines on membrane functions. Biochem. J. 260, 1-10.

Seiler, N., Schmidt-Glenewinkel, T., and Sarhan, S. (1979). On the formation of gamma-aminobutyric acid from putrescine in brain. J. Biochem. 86, 277-278.

Shevyakova, N. I., Musatenko, L. I., Stetsenko, L. A., Rakitin, V. Y., Vedenicheva, N. P., and Kuznetsov, V. V. (2013). Effect of ABA on the contents of proline, polyamines, and cytokinins in the common ice plants under salt stress. Russ. J. Plant Physiol. 60, 741-748. doi: 10.1134/S1021443713060125

Shore, L. J., Soler, A. P., and Gilmour, S. K. (1997). Ornithine decarboxylase expression leads to translocation and activation of protein kinase CK2 in vivo. J. Biol. Chem. 272, 12536-12543. doi: 10.1074/jbc.272.19.12536

Sorais, F., Nino-Vega, G., and San-Blas, G. (2003). Mechanisms of degradation of the fungal ornithine decarboxylase. Rev. Iberoam. Micol. 20, 1-5.

Soyka, S., and Heyer, A. G. (1999). Arabidopsis knockout mutation of ADC2 gene reveals inducibility by osmotic stress. FEBS Lett. 458, 219-223. doi: 10.1016/S0014-5793(99)01125-4

Stark, F., Pfannstiel, J., Klaiber, I., and Raabe, T. (2011). Protein kinase CK2 links polyamine metabolism to MAPK signalling in Drosophila. Cell. Signal. 23 , 876-882. doi: 10.1016/j.cellsig.2011.01.013

Storz, G., and Imlay, J. A. (1999). Oxidative stress. Curr. Opin. Microbiol. 2, 188-194. doi: 10.1016/S1369-5274(99)80033-2

Suh, S. O., Blackwell, M., Kurtzman, C. P., and Lachance, M. A. (2006). Phylogenetics of Saccharomycetales, the ascomycete yeasts. Mycologia 98, 1006-1017. doi: 10.3852/mycologia.98.6.1006

Suzuki, N., Koussevitzky, S., Mittler, R., and Miller, G. (2012). ROS and redox signalling in the response of plants to abiotic stress. Plant Cell Environ. 35, 259-270. doi: $10.1111 /$ j.1365-3040.2011.02336.x

Tabor, C. W., and Tabor, H. (1984). Polyamines. Annu. Rev. Biochem. 53, 749-790. doi: 10.1146/annurev.bi.53.070184.003533

Takano, A., Kakehi, J., and Takahashi, T. (2012). Thermospermine is not a minor polyamine in the plant kingdom. Plant Cell Physiol. 53, 606-616. doi: $10.1093 / \mathrm{pcp} / \mathrm{pcs} 019$

Tanou, G., Ziogas, V., Belghazi, M., Christou, A., Filippou, P., Job, D., et al. (2013). Polyamines reprogram oxidative and nitrosative status and the proteome of citrus plants exposed to salinity stress. Plant Cell Environ. doi: 10.1111/pce.12204. [Epub ahead of print].

Tavladoraki, P., Schinina, M. E., Cecconi, F., Di Agostino, S., Manera, F., Rea, G., et al. (1998). Maize polyamine oxidase: primary structure from protein and cDNA sequencing. FEBS Lett. 426, 62-66. doi: 10.1016/S0014-5793(98)00311-1

Thomas, D., Rothstein, R., Rosenberg, N., and Surdin-Kerjan, Y. (1988). SAM2 encodes the second methionine S-adenosyl transferase in Saccharomyces cerevisiae: physiology and regulation of both enzymes. Mol. Cell. Biol. 8, 5132-5139.

Tkachenko, A., Nesterova, L., and Pshenichnov, M. (2001). The role of the natural polyamine putrescine in defense against oxidative stress in Escherichia coli. Arch. Microbiol. 176, 155-157. doi: 10.1007/s002030100301

Toth, C., and Coffino, P. (1999). Regulated degradation of yeast ornithine decarboxylase. J. Biol. Chem. 274, 25921-25926. doi: 10.1074/jbc.274.36.25921

Urano, K., Yoshiba, Y., Nanjo, T., Igarashi, Y., Seki, M., Sekiguchi, F., et al. (2003). Characterization of Arabidopsis genes involved in biosynthesis of polyamines in abiotic stress responses and developmental stages. Plant Cell Environ. 26, 1917-1926. doi: 10.1046/j.1365-3040.2003.01108.x

Valdes-Santiago, L., Cervantes-Chavez, J. A., Leon-Ramirez, C. G., and RuizHerrera, J. (2012a). Polyamine metabolism in fungi with emphasis on phytopathogenic species. J. Amino Acids 2012:837932. doi: 10.1155/2012/837932

Valdés-Santiago, L., Cervantes-Chavez, J. A., Winkler, R., Leon-Ramirez, C. G., and Ruiz-Herrera, J. (2012b). Phenotypic comparison of samdc and spe mutants reveals complex relationships of polyamine metabolism in Ustilago maydis. Microbiology 158, 674-684. doi: 10.1099/mic.0.055954-0

Valdes-Santiago, L., Cervantes-Chavez, J. A., and Ruiz-Herrera, J. (2009). Ustilago maydis spermidine synthase is encoded by a chimeric gene, required for morphogenesis, and indispensable for survival in the host. FEMS Yeast Res. 9, 923-935. doi: 10.1111/j.1567-1364.2009.00539.x
Valdes-Santiago, L., Guzman-De-Pena, D., and Ruiz-Herrera, J. (2010). Life without putrescine: disruption of the gene-encoding polyamine oxidase in Ustilago maydis odc mutants. FEMS Yeast Res. 10, 928-940. doi: 10.1111/j.15671364.2010.00675.x

Velarde-Buendia, A. M., Shabala, S., Cvikrova, M., Dobrovinskaya, O., and Pottosin, I. (2012). Salt-sensitive and salt-tolerant barley varieties differ in the extent of potentiation of the ROS-induced $\mathrm{K}(+)$ efflux by polyamines. Plant Physiol. Biochem. 61, 18-23. doi: 10.1016/j.plaphy.2012.09.002

Vujcic, S., Liang, P., Diegelman, P., Kramer, D. L., and Porter, C. W. (2003). Genomic identification and biochemical characterization of the mammalian polyamine oxidase involved in polyamine back-conversion. Biochem. J. 370, 19-28. doi: 10.1042/BJ20021779

Wallace, H. M., Fraser, A. V., and Hughes, A. (2003). A perspective of polyamine metabolism. Biochem. J. 376, 1-14. doi: 10.1042/BJ20031327

Walters, D. (2003). Resistance to plant pathogens: possible roles for free polyamines and polyamine catabolism. New Phytol. 159, 109-115. doi: 10.1046/j.14698137.2003.00802.x

Ware, D., Jiang, Y., Lin, W., and Swiatlo, E. (2006). Involvement of potD in Streptococcus pneumoniae polyamine transport and pathogenesis. Infect. Immun. 74, 352-361. doi: 10.1128/IAI.74.1.352-361.2006

Watanabe, M., Watanabe, D., and Kondo, S. (2012). Polyamine sensitivity of gap junctions is required for skin pattern formation in zebrafish. Sci. Rep. 2, 473 doi: 10.1038/srep00473

Weerasooriya, M. K. B., Handagiripathira, H. M. N. L., and Wijewickrama, G. T. (2003). Arginine decarboxylase from the pathogenic fungi, Colletotrichum gleosporoides: purification and properties. J. Sci. Univ. Kelaniya 1, 23-34.

Williams, L. J., Barnett, G. R., Ristow, J. L., Pitkin, J., Perriere, M., and Davis, R. H. (1992). Ornithine decarboxylase gene of Neurospora crassa: isolation, sequence, and polyamine-mediated regulation of its mRNA. Mol. Cell. Biol. 12, 347-359.

Wortham, B. W., Oliveira, M. A., Fetherston, J. D., and Perry, R. D. (2010). Polyamines are required for the expression of key Hms proteins important for Yersinia pestis biofilm formation. Environ. Microbiol. 12, 2034-2047. doi: 10.1111/j.1462-2920.2010.02219.x

Wysong, D. R., Christin, L., Sugar, A. M., Robbins, P. W., and Diamond, R. D. (1998). Cloning and sequencing of a Candida albicans catalase gene and effects of disruption of this gene. Infect. Immun. 66, 1953-1961.

Xue, B., Zhang, A., and Jiang, M. (2009). Involvement of polyamine oxidase in abscisic acid-induced cytosolic antioxidant defense in leaves of maize. J. Integ. Plant Biol. 51, 225-234. doi: 10.1111/j.1744-7909.2008.00766.x

Yamada, H., Isobe, K., and Tani, Y. (1980). Oxidation of polyamines by fungal enzymes. Agric. Biol. Chem. 44, 2469-2476. doi: 10.1271/bbb1961.44.2469

Yamaguchi, K., Takahashi, Y., Berberich, T., Imai, A., Miyazaki, A., Takahashi, T., et al. (2006). The polyamine spermine protects against high salt stress in Arabidopsis thaliana. FEBS Lett. 580, 6783-6788. doi: 10.1016/j.febslet.2006.10.078

Yoda, H., Yamaguchi, Y., and Sano, H. (2003). Induction of hypersensitive cell death by hydrogen peroxide produced through polyamine degradation in tobacco plants. Plant Physiol. 132, 1973-1981. doi: 10.1104/pp.103.024737

Zhang, M., Pickart, C. M., and Coffino, P. (2003). Determinants of proteasome recognition of ornithine decarboxylase, a ubiquitin-independent substrate. EMBO J. 22, 1488-1496. doi: 10.1093/emboj/cdg158

Conflict of Interest Statement: The authors declare that the research was conducted in the absence of any commercial or financial relationships that could be construed as a potential conflict of interest.

Received: 28 November 2013; paper pending published: 07 December 2013; accepted: 24 December 2013; published online: 10 January 2014.

Citation: Valdés-Santiago L and Ruiz-Herrera J (2014) Stress and polyamine metabolism in fungi. Front. Chem. 1:42. doi: 10.3389/fchem.2013.00042

This article was submitted to Plant Metabolism and Chemodiversity, a section of the journal Frontiers in Chemistry.

Copyright (C) 2014 Valdés-Santiago and Ruiz-Herrera. This is an open-access article distributed under the terms of the Creative Commons Attribution License (CC BY). The use, distribution or reproduction in other forums is permitted, provided the original author(s) or licensor are credited and that the original publication in this journal is cited, in accordance with accepted academic practice. No use, distribution or reproduction is permitted which does not comply with these terms. 